\title{
Application of encapsulated natural bioactive compounds from red pepper waste in yogurt
}

\section{Vanja Šeregelj, Vesna Tumbas Šaponjac, Steva Lević, Ana Kalušević, Gordana Ćetković, Jasna Čanadanović-Brunet, Viktor Nedović, Slađana Stajčić, Jelena Vulić \& Ana Vidaković}

To cite this article: Vanja Šeregelj, Vesna Tumbas Šaponjac, Steva Lević, Ana Kalušević,

Gordana Ćetković, Jasna Čanadanović-Brunet, Viktor Nedović, Slađana Stajčić, Jelena Vulić \& Ana Vidaković (2019): Application of encapsulated natural bioactive compounds from red pepper waste in yogurt, Journal of Microencapsulation, DOI: 10.1080/02652048.2019.1668488

To link to this article: https://doi.org/10.1080/02652048.2019.1668488

Accepted author version posted online: 13

Sep 2019.

Submit your article to this journal $\sqsubset \pi$

Џ Article views: 4

Q View related articles ¿

View Crossmark data $\asymp$ 


\title{
Application of encapsulated natural bioactive compounds from red pepper waste in yogurt
}

\author{
Vanja Šeregelj*a, Vesna Tumbas Šaponjac ${ }^{a}$, Steva Lević ${ }^{b}$, Ana Kaluševićc \\ c, Gordana Ćetkovića, Jasna Čanadanović-Brunet ${ }^{\mathrm{a}}$, Viktor Nedović ${ }^{\mathrm{b}}$, \\ Slađana Stajčića ${ }^{\mathrm{a}}$, Jelena Vulića ${ }^{\text {, Ana Vidakovićd }}{ }^{\mathrm{d}}$
}

${ }^{a}$ Department of Applied and Engineering Chemistry, University of Novi Sad, Faculty of Technology Novi Sad, Serbia,vvanjaseregelj@tf.uns.ac.rs, vesnat11@uns.ac.rs, cetkovic@tf.uns.ac.rs,jasnab@uns.ac.rs,sladja@uns.ac.rs,jvulic@uns.ac.rs

${ }^{b}$ University of Belgrade, Faculty of Agriculture, Department of Food Technology and Biochemistry, Nemanjina 6, Zemun, Serbia, stevalevic@gmail.com, ana.kalusevic@agrif.bg.ac.rs,vnedovic@agrif.bg.ac.rs

c Institute of Meat Hygiene and Technology, Belgrade, Serbia, anakalusevic@gmail.com

${ }^{d}$ Department of Biotechnology and Pharmaceutical Engineering, University of Novi Sad, Faculty of Technology Novi Sad, Serbia, anav@uns.ac.rs

Address for correspondence: Vanja Šeregelj, Research Assistant, Department of Applied and Engineering Chemistry, University of Novi Sad, Faculty of Technology Novi Sad, Serbia, +38121458736; email:vanjaseregelj@tf.uns.ac.rs 


\section{Application of encapsulated natural bioactive compounds from red pepper waste in yogurt}

Aim: The aim of study was to encapsulate red pepper waste (RPW) bioactives and monitor their stability in yogurt.

Methods: RPW extract was encapsulated in whey protein using spray and freeze drying techniques. Physicochemical characteristics of encapsulates were evaluated, and better encapsulates were used to develop functional yogurt. Retention of bioactives was followed over 21 days of storage, and sensory analyses were assessed.

Results: Freeze dried encapsulates (FDE) showed better characteristics like water activity, moisture content, solubility, flowing and colour properties, and therefore incorporated in yogurt. Yogurt with FDE successfully retained carotenoids (71.43\%) and caused increasing of polyphenol retention (up to 123.73\%). This yogurt exhibited higher sensory and general acceptability scores compared to control sample. The fortification of yogurts had positive influence on maintaining the initial number of lactic acid bacteria during storage.

Conclusion: Freeze drying and utilization of pepper waste are efficient for functional food development, with improved nutritional, colour and bioactive properties.

Keywords: Red pepper waste, carotenoids, polyphenols, encapsulation, yogurt fortification

\section{Introduction}

Valorisation of food wastes for edible purposes represents a challenging field for researchers. Losses along the production chain vary from 20 to almost $50 \%$ regarding to raw materials group. The largest losses during processing are among fruit and vegetables as raw materials (Gustavsson et al. 2011). Considering that vegetables processing wastes contain significant amounts of valuable compounds derived from the original material, they have the potential to be reused into numerous added-value and marketable products rather than usual products of food waste utilization (e.g. energy, feed and fertilizers) (Nedović et al. 2017). Yogurt is one of the most popular and worldwide consumed dairy product due to its organoleptic and nutritional properties. 
Today, food market gives a wide range of yogurt formulations prepared using specific additives such as colorants and antioxidants. However, the recent concerns about the safety of artificial colourants in food products have encouraged the development and application of natural ones (Pop et al. 2010). Beyond their primary effect, natural colourants can provide better sensorial, nutritional, and antioxidant quality of final product (Caleja et al. 2016).

Peppers belong to the genus Capsicum, are vegetables usually processed into two types of products: (a) dehydrated, pickled, and sliced/diced frozen peppers; (b) products such as pepper sauce, paste, puree and powders (FiratligilDurmus and Evranuz, 2010). Utilization of solid wastes remaining after pepper products processing that consist of peel, stems, leaves and seeds is of an important food industry interest. The pericarp of the pepper fruit is a plant tissue that accumulates considerable amounts of numerous carotenoid pigments, giving the ripe fruit intensive colours. The carotenoid pigments have been divided in red and yellow fractions: diesterified capsanthin and capsorubin; and $\beta$-carotene, esterified cryptoxanthin and diesterified zeaxanthin, respectively (MinguezMosquera et al. 2000). From economical and environmental standpoint, pepper processing waste represents desirable raw material for the production of food colourants. However, polyenoic chain as the structural characteristic of carotenoid pigments allows carotenoids to be degraded by oxidation processes. Also, it has been reported that stability of the main carotenoids depends on temperature, residual moisture content, increased surface area etc. (Markus et al. 1999). Peppers are also rich in phenolic compounds, which contribute to fruit sensory and nutritive quality in terms of modifying colour, taste, aroma and flavour, and also providing health-beneficial effects (Khan et al. 2014). 
Therefore, encapsulation technology could be applied in order to improve carotenoid pigments stability. Encapsulation can be used to improve their bioavailability and modify time and/or place of their release upon administration. In general, some of the most suitable preservation methods for vegetable juices and extracts are the spray and freeze drying processes. Their main advantages over the other encapsulation techniques are simplicity, continuity, effectiveness, availability and applicability (Nedović et al. 2013). Development of encapsulates in form of powders with improved physical properties and higher yields is enabled due to the addition of numerous carrier materials. Encapsulation has proved as a convenient strategy to prevent carotenoid degradation avoiding oxygen-mediated auto-oxidation reactions, although its results depend on carrier material properties (Raskon et al. 2011).

Encapsulation of carotenoids (paprika oleoresin, rosa mosqueta oleoresin carrot carotenes, pure $\beta$-carotene) by spray drying has been widely investigated using the different carrier materials (maltodextrin of different DE, Arabic gum, gelatin, sodium caseinate). Contrary to spray drying, encapsulation of carotenoids by freeze drying has been infrequently reported.

Among wide range of carrier materials, whey protein isolate has been applied in this study for significant commercial potential as a by-product of cheese production, with superior gelling and emulsification properties, rich in $\beta$ lactoglobulin and $\alpha$-lactalbumin. Furthermore, it is a suitable vehicle for different bioactive compounds based on sustained antioxidative activity throughout simulated digestion models (Tumbas Šaponjac et al. 2016). Additionally, the use of this material may represent an additional improvement in the nutritional value of the final product. Thus, encapsulated extract of pepper 
waste could be used in the food industry as a colourant in the production of diary and meat products, potato chips, popcorn, salads, mayonnaise, soups, sauces, jams, beverages, and bakery additives, but feed, as well (Raskon et al. 2011).

The objective of this study was to investigate possibility of utilization of pepper processing waste, as a by-product and source of bioactives, and to investigate the influence of different encapsulation techniques on functionality of the obtained encapsulates as potential food additives. The study was designed to investigate the possibility to develop functional yogurt, fortified with encapsulated carotenoid and phenolic compounds, their stability during the 21 days storage period, as well as microbiological analysis and sensory attributes of the final products.

\section{Material and Methods}

\section{Plant Material}

Fresh red pepper waste (RPW) material was obtained as by-product from the vegetable processing industry ("Zdravo Organic", Selenča, Serbia). Waste material was freeze dried, ground, packed in vacuumed plastic bags and stored at $-20{ }^{\circ} \mathrm{C}$ until further analysis.

\section{Extraction procedure}

Freeze dried RPW was extracted using $100 \%(\mathrm{v} / \mathrm{v})$ acetone or mixture of $36 \%$ (v/v) acetone and $64 \%$ (v/v) ethanol following the method described by Šeregelj et al. (2016). The obtained extracts were stored in dark bottles at $-20{ }^{\circ} \mathrm{C}$ until further analysis. 


\section{Characterization of RPW extracts}

Determination of bioactive compounds

Total carotenoid content (TCar) in RPW extracts, expressed as mg of $\beta$-carotene equivalents per $100 \mathrm{~g}$ dry sample (mg $\beta$-carotene/100g), was analyzed spectrophotometrically by the method of Nagata and Yamashita (1992). Total phenolic content (TPh), expressed as gallic acid equivalents (GAE) per $100 \mathrm{~g}$ dry sample (mg GAE/100g), was determined spectrophotometrically by FolinCiocalteau method adapted to microscale. For HPLC analysis of carotenoids solvent gradient was performed by varying the proportion of solvent A (20\% $(\mathrm{v} / \mathrm{v})$ water and $80 \%(\mathrm{v} / \mathrm{v})$ methanol) to solvent B (50\% (v/v) acetone and 50\% $(\mathrm{v} / \mathrm{v})$ methanol) at flow rates of $1 \mathrm{~mL} / \mathrm{min}$ with the following gradient profile: 25\% B 0-3 min; 75\% B 3-6 min; 90\% B 6-10 min; $100 \%$ B 10-18 min; 50\% B 18-25 min; $25 \%$ B 25-32 min. The column temperature was $25{ }^{\circ} \mathrm{C}$ and chromatograms were plotted at 450 and $475 \mathrm{~nm}$. Carotenoids were dissolved in hexane and identified by matching the retention time and its spectral characteristics against those of standards. Phenolic compounds were recorded using different wavelengths: $280 \mathrm{~nm}$ for hydroxybenzoic acids, $320 \mathrm{~nm}$ for hydroxycinnamic acids and $360 \mathrm{~nm}$ for flavonoids (Tumbas Šaponjac et al. 2015).

\section{Determination of antioxidant activity}

The antioxidant activity, expressed as $\mu \mathrm{mol}$ Trolox equivalent (TE) per $100 \mathrm{~g}$ of dry sample (mg TE/100g), was determined by 2,2-diphenyl-1-picrylhydrazyl method $\left(\mathrm{AC}_{\mathrm{DPPH}}\right)$ described by Girones-Vilaplana et al. (2014), reducing power (RP) by the Oyaizu (1986), and 2,2'-azino-bis-3-ethylbenzothiazoline-6sulphonic acid method $\left(\mathrm{AC}_{\mathrm{ABTS}}\right)$ by Tumbas Šaponjac et al. (2014). The 
antioxidant capacity of extracts was also evaluated by the $\beta$-carotene-linoleate model system $\left(\mathrm{AC}_{\mathrm{BCB}}\right)$. $\mathrm{BHA}$ was used for comparison in the concentration of $0.05 \mathrm{mg} / \mathrm{mL}$. Absorbances were read after $180 \mathrm{~min}$ (Al-Shaikan et al. 1995).

\section{Encapsulation process}

Freeze and spray dried encapsulates were prepared following the method described by Šeregelj et al. (2016). WPI (7 g) was dissolved in $10 \mathrm{ml}$ of water at $60{ }^{\circ} \mathrm{C}$ and kept under stirring until the temperature reached $30{ }^{\circ} \mathrm{C}$, while the mixture for spray drying was dissolved in the same way in $40 \mathrm{~mL}$ of water. Separately, $40 \mathrm{~mL}$ of RPW extract was combined with sunflower oil (1.5 mL), concentrated under reduced pressure on a rotary evaporator set at $40{ }^{\circ} \mathrm{C}$ to remove the organic solvent, and immediately mixed with previously prepared carrier solution. The mixtures were homogenized at $11000 \mathrm{rpm}$ for $3 \mathrm{~min}$ at room temperature and subjected to drying.

Spray drying conditions

The homogenized mixture was spray dried using a laboratory scale spray dryer (Buchi mini B-290, Büchi Labortechnik, Switzerland) at an inlet temperature of $130{ }^{\circ} \mathrm{C}$ and an outlet temperature of $65 \pm 2{ }^{\circ} \mathrm{C}$. The spraying air flow rate and rate of liquid feed were $600 \mathrm{~L} / \mathrm{h}$ and $8 \mathrm{~mL} / \mathrm{min}$, respectively.

\section{Freeze drying conditions}

The previously prepared mixture was iced overnight at $-20{ }^{\circ} \mathrm{C}$ and then freeze dried (Christ Alpha 2-4 LSC, Martin Christ, Germany) at $-40{ }^{\circ} \mathrm{C}$ for $48 \mathrm{~h}$ to ensure complete drying. Collected freeze dried encapsulate (FDE) was stored at $-20{ }^{\circ} \mathrm{C}$ until further use. 


\section{Characterization of the RPW encapsulates}

Water activity $\left(\mathrm{a}_{\mathrm{w}}\right)$ was determined by a LabSwift-aw meter (Novasina, Switzerland) at $25^{\circ} \mathrm{C}$. The moisture content of encapsulates was measured using air oven method at $105{ }^{\circ} \mathrm{C}$ until a constant weight was obtained. For hygroscopicity $2 \mathrm{~g}$ of each encapsulate from the Petri dishes were placed at 25 ${ }^{\circ} \mathrm{C}$ in an airtight plastic container filled with $\mathrm{NaCl}$ saturated solution $(75.29 \%$ $\mathrm{RH})$. After 1 week, hygroscopicity was weighed and expressed as $\mathrm{g}$ of moisture per $100 \mathrm{~g}$ dry solids. Solubility tests were carried out by adding each powder ( 50 $\mathrm{mg})$ to water $(1 \mathrm{~mL})$ at room temperature $\left(20^{\circ} \mathrm{C}\right)$. The obtained mixtures were vortexed and the time taken to fully reconstitute the powders was recorded. Bulk (Db) and tapped density (Dt) of the samples were determined using the method described in the European Pharmacopeia (Council of Europe, 2010). Carr's Index $(\mathrm{CI})$ and Hausner ratio were calculated as $\mathrm{CI}=[(\mathrm{Dt}-\mathrm{Db}) / \mathrm{Dt}] \times 100$ and Hausner Ratio $=\mathrm{Dt} / \mathrm{Db}$, respectively. The particle size distribution of the obtained powders was determined using the Mastersizer 2000 laser diffraction size analyzer (Malvern Instruments, Worcestershire, UK) equipped with the Scirocco2000 dispersion unit. The size distribution was quantified as relative volume of particles in size bands presented as size distribution curves using Mastersizer 2000 Software. Contents of surface carotenoid (SC) and total carotenoid (TC) in the RPW encapsulates, as well as encapsulation efficiency (EE Car) were determined by Barbosa et al. (2005) method. The control sample has been simultaneously prepared by replacing encapsulate extract with matching concentration of WPI extract in the same way. For surface phenolics (SP) and total phenolics (TP) in the RPW encapsulates, as well as encapsulation efficiency (EE Ph) were determined by Tumbas Šaponjac et al. (2016). Simultaneously, the control sample of WPI has been also made. The colour 
measurements were made with a Minolta reflectance colorimeter (Minolta ChromaMeter CR-300, Minolta, Osaka, Japan) considering the CIELab colour system. Chroma or saturation $\left(\mathrm{C}^{*}\right)$ was calculated according to the following formula: $C^{*}=\sqrt{ }\left(a^{*} 2+b * 2\right)$.

FTIR spectra of RPW extract, WPI, sunflower oil, FDE and SDE were acquired using a spectrometer IRAffinity-1 (SHIMADZU, Japan). Spectra were collected in the spectral range $4000-500 \mathrm{~cm}^{-1}$, with the resolution of $4 \mathrm{~cm}^{-1}$. Prior to analysis, the powdered samples (i.e. WPI, FDE and SDE) were mixed with $\mathrm{KBr}$, pulverized and compressed into pellets. The spectra of sunflower oil and pepper extract were recorded using blank $\mathrm{KBr}$ pellet as holder for liquid samples. RPW extract was placed on the pellet's surface (total $50 \mu \mathrm{L}$ ), in two portions, followed by solvent evaporation at room temperature. After solvent removal, the FTIR spectrum of RPW extract was recorded as explained above. Raman spectra were collected with XploRA Raman spectrometer from Horiba Jobin Yvon (Kyoto, Japan). The system employed laser at $785 \mathrm{~nm}$. All measurements were carried out using the spectrometer equipped with a $1800 \mathrm{gr} / \mathrm{mm}$ grating. The study of samples morphological properties has been carried out by JEOL JSM-6390LV scanning electron microscope (SEM). Prior to the analysis the samples were covered with Au using a sputter coater Baltec scd 005 (30mA for 100s).

\section{Yogurt fortification}

Natural yogurt "BALANS" produced by Imlek dairy industry (Belgrade, Serbia), was purchased in a local supermarket. The yogurt base was mixed with FDE in the concentration of $10 \%(\mathrm{w} / \mathrm{v})$, while the control sample was prepared with dry RPW extract, containing the same amount of carotenoids. The stability of encapsulated and non-encapsulated bioactive compounds from RPW in yogurt 
was assessed during 21 days of storage at $4{ }^{\circ} \mathrm{C}$. TCar and TPh in both yoghurt samples were evaluated every 3rd day during the storage time.

\section{TCar estimation in yogurt samples}

Yogurt sample with FDE and with dry RPW extract $(1 \mathrm{~mL})$ was exhaustively extracted using mixture containing 75\% (v/v) chloroform and 25\% (v/v) methanol, followed by centrifugation at $4000 \mathrm{rpm}$ and collection of supernatants. The carotenoid quantification was carried out according to the previously described protocol.

TPh estimation in yogurt samples

Extraction of yogurt samples for the estimation of $\mathrm{TPh}$ was carried out according to Shori et al. (2018). TPh in extracted yogurt samples were determined using the above described Folin-Ciocalteu assay.

\section{Microbiological analysis}

Total number of lactic acid bacteria (LAB) was determined according to the standardized method for enumeration of characteristic microorganisms in yogurt (ISO 7889, 2003). The enumeration of LAB in the yogurt samples was performed at the beginning of the experiment and after 21 days of refrigerated storage at $4{ }^{\circ} \mathrm{C}$.

\section{Sensory attributes}

Sensory evaluation was assessed by a trained panel of seven members using five-point hedonic scale (Karagul-Yuceer and Drake, 2006). Panelists appraised colour and appearance, odour, flavour, body and texture, and general acceptability. 


\section{Statistical analysis}

All experiments were run in triplicate and results were represented as means \pm standard deviation. Statistical analyses were carried out using Origin 8.0 SRO software package and Microsoft Office Excel 2010. Significant differences were calculated by ANOVA $(\mathrm{p}<0.05)$.

\section{Results and Discussion}

\section{Characterization of RPW extracts}

The recovery of bioactive compounds is dependent on the employed extraction solvent. Table 1 summarizes the influence of solvents having different polarity on the extraction efficiency of total and individual carotenoids and phenolics. The ANOVA showed significant differences among RPW extracts in content for all bioactive compounds.

\section{Table 1.}

Spectrophotometrically analysis of TCar showed that acetone:ethanol mixture extracted more carotenoids than pure acetone. Batra et al. (2017) reported that the content of carotenoids in red peppers vary from 442.4 to $500.1 \mu \mathrm{g} / \mathrm{g}$ dry weight. Different reports showed that content of bioactive compounds in peppers vary with cultivars, maturity stage, and processing conditions. Total extractable phenolics in RPW were determined spectrophotometrically by Folin-Ciocalteu assay, with significant variation in the yield among different solvents. Turkmen et al. (2006) reported that solvents with different polarity had significant effect on polyphenol contents in extracts, and that antioxidant activity is higher in extracts obtained with more polar solvents. Our results are in agreement with this observation, where $\mathrm{TPh}$ yield was $58.12 \%$ higher in acetone:ethanol than in acetone extract. TPh yield found in acetone:ethanol RPW extract was higher 
than yield given for $80 \%$ ethanol pepper extract (Zhuang et al. 2012). The characterization of individual carotenoids and phenolics was conducted by HPLC analysis. The red colour of pepper is imparted by carotenoids with more than 50 identified structures. As the previously published papers reported only some of the carotenoids in RPW extracts were quantified $\beta$-carotene, lutein, zeaxanthin, and $\beta$-cryptoxanthin. In acetone extract, $\beta$-carotene was found in highest level $(6.45 \mathrm{mg} / 100 \mathrm{~g})$, followed by $\beta$-cryptoxanthin $(2.22 \mathrm{mg} / 100 \mathrm{~g})$, zeaxanthin $(0.53 \mathrm{mg} / 100 \mathrm{~g})$, and lutein $(0.47 \mathrm{mg} / 100 \mathrm{~g})$. Acetone:ethanol extract also exhibited the highest level of $\beta$-carotene $(6.51 \mathrm{mg} / 100 \mathrm{~g})$, followed by lutein (4.03 mg/100g), zeaxanthin (1.07 mg/100g), and $\beta$-cryptoxanthin (0.21 $\mathrm{mg} / 100 \mathrm{~g}$ ). In five cultivars of red pepper, Russo and Howard (2002) beside capsanthin, also detected $2.2 \mathrm{mg} / \mathrm{g}$ of lutein, $0.8-5.9 \mathrm{mg} / \mathrm{g}$ of zeaxanthin, $0.6-6.8$ $\mathrm{mg} / \mathrm{g}$ of $\beta$-carotene, and $0.8-4.3 \mathrm{mg} / \mathrm{g}$ of $\beta$-cryptoxanthin. Data of HPLC analysis revealed presence of three hydroxybenzoic acids (gallic, vanillic, and protocatehuic acid), four hydroxycinnamic acids (sinapic, caffeic, rosmarinic, and chlorogenic acid), one flavan-3-ols (epicatechin) and three flavnols (rutin, quercetin, and myricetin). Phenolic compounds in acetone:ethanol extract were generally higher than those in acetone extract, except for vanillic, chlorogenic acid, and all flavonoids. Similar phenolic and flavonoid profiles have been also reported in scalded Jalapeno pepper industrial by-product and some Egyptian sweet peppers (Sandoval-Castro et al. 2017; Shaimaa et al. 2016).

In the present study, $\mathrm{AC}_{\mathrm{DPPH}}, \mathrm{RP}, \mathrm{AC}_{\mathrm{ABTS}}$, and $\mathrm{AC}_{\mathrm{BCB}}$ were used to evaluate the antioxidant activity of RPW extracts (Table 1). Significant differences were calculated by ANOVA, and it can be concluded that the extract obtained using solvent with higher polarity (acetone:ethanol mixture) was considerably more 
effective radical scavenger on $\mathrm{DPPH}^{\bullet}$ and $\mathrm{ABTS}^{\bullet}$ radicals, and also possess higher reducing power than acetone extract. Ghasemzadeh et al. (2010) suggested that the free radical scavenging power of antioxidant compounds is associated with their TPh. This observation coincides with our results and can be confirmed relationship between TPh and antioxidant capacity in RPW extracts. In the $\beta$-carotene bleaching assay, after 180 min of incubation, no significantly higher $(\mathrm{P}<0.05)$ ACBCB was recorded for acetone:ethanol extract $(74.08 \%)$ than acetone extract (73.29\%). However, the ACBCB of both RPW extracts was lower than the activity of standard BHA $(89.71 \%)$.

\section{RPW encapsulation and characterization of obtained encapsulates}

Bioactive compounds, such as carotenoids and polyphenols, are relatively unstable in food systems and can be easily degraded by oxygen or light during storage or manufacture of foods. These cause the loss of their nutritive and biological properties, as well as the production of undesirable flavour. Therefore, two different encapsulation techniques were used to overcome the above mentioned drawbacks. The effects of different drying methods on physical characteristics of RPW encapsulates are presented in Table 2, and ANOVA showed significant differences among samples for all the traits assessed.

\section{Table 2}

In the field of food science, aw values vary with moisture content as it measures the availability of free water in a food system which is responsible for many biochemical reactions (Que et al. 2007). It can be observed that FDE had lower water activity (0.029) than SDE (0.252). Lower $a_{w}$ values indicate unsuitable environment for microorganism growth, and thus contribute a longer product 
shelf life. Also, our results are in agreement with moisture content which indicated that FDE had lower moisture content compared to SDE (Table 2). Further, hygroscopicity is considered as one of the most important quality factors for long-term storage and corresponded to the moisture content, which means that the higher moisture content indicates higher hygroscopic value. The hygroscopicity of FDE was lower $(4.94 \mathrm{~g} / 100 \mathrm{~g})$ than for SDE $(7.28 \mathrm{~g} / 100 \mathrm{~g})$, confirming the link between these two characteristics. Solubility or behaviour of encapsulates in aqueous solution was also evaluated in this study. FDE exhibited higher solubility than $\operatorname{SDE}(97.69 \%$ and $84.22 \%$, respectively). It is hypothesized that drying process affects the position of hydrophobic and hydrophilic amino acids in the interior or exterior layer of the protein molecule, thus affecting the solubility of the protein. The different sets of strong covalent bonds or weak non-covalent bonds (i.e. such as Van der Waals attractions, hydrogen, and ionic bonds) that form between one part of the protein chain and another can significantly alter the solubility of the protein. The interaction between water and protein molecules can build up new hydrogen bonds with the amide nitrogen and carbonyl oxygen of peptide bonds. These interactions result in the further weakness nearby hydrogen bonds, thus affecting the solubility and functional properties of protein fraction (Alberts et al. 2007). High solubility of FDE may be attributed to the high content of hydrophilic fraction and soluble materials as well as its low cross-linking (Rao et al. 2002).

Measurement of bulk density and tapped density is essential for food encapsulates since they allow the adjustment for storage, processing, packaging of encapsulates (Barbosa-Canovas et al. 2005). Higher moisture content in encapsulate will increase the tendency of powder to stick together, resulting in 
powder bulk density decrease (Goula and Adamopoulos, 2005). This justifies that SDE powder has lower bulk density due to its higher moisture content. FDE with lower moisture content showed good flowability (17.14\%) and intermediate (1.21) cohesiveness. However, SDE with higher moisture showed inferior flow properties, regarding bad flowability (40.54\%) and high cohesiveness (1.68). Particle size and particle size distribution also displayed major impact on encapsulate flowability and cohesiveness. According to Jinapong et al. (2008), larger particle size has better flowability and decreased cohesiveness. This observation was confirmed in this research where FDE, with significantly larger particle size and surface-weighted mean diameter (Dsr) of $174.57 \mu \mathrm{m}$, had better flowability and cohesiveness compared to SDE with lower Dsr $(14.57 \mu \mathrm{m})$ (Table 2). Smaller particles have higher surface area and result in higher cohesion and attrition force formation that lead to resistance to powder flow (Victória et al. 2013). The largest particle size of freeze dried samples is due to the low process temperature, and the lack of strength to break the frozen drops or to alter the surface during drying (Chen et al. 2012). The Span values were higher than 1 , characterizing a very broad distribution of particle sizes for both encapsulates.

EE indicate the content of encapsulated bioactive compounds, which are strongly affected by process conditions and applied wall materials. EE Car and EE Ph values were higher for freeze dried sample (53\% and 79\%, respectively) than for spray dried sample ( $41 \%$ and $66 \%$, respectively). The difference in EE could be explained due to the susceptibility of carotenoids and some phenolics to degradation during the application of heat in the spray drying process (Changchub and Maisuthisakul, 2011). 
Colour is one of the major attributes which affects the consumer perception of quality. Results of colour measurements of encapsulates are expressed by L*, a*, and $b^{*}$ components (Table 2). Applied drying processes had a significant effect on the colour of the obtained pigment encapsulates. The degree of lightness, i.e. L* values, revealed that FDE has darker colour compared to SDE. The apparent colour of red pepper is featured by a mix of redness and yellowness due to the presence of carotenoids. Larger $a^{*}$ and $b^{*}$ values for FDE indicate deeper red and yellow colour compared to SDE, which could be explained by the destruction of carotenoids in the sample due to the application of heat during spray drying. The decrease in particle size caused an increase in lightness and a decrease in the redness and yellowness.

FTIR analysis was applied in order to investigate the potential interactions between encapsulate components and to confirm the presence of the individual components. FTIR spectrum of the RPW extract (Fig. 1A) shows the bands that could be associated with carotenoids at $3394 \mathrm{~cm}^{-1}$ (OH groups), $2922 \mathrm{~cm}^{-1}$ (C-H bound) and weak band at $1737 \mathrm{~cm}^{-1}(\mathrm{C}=\mathrm{O})$, while the bands around $1400 \mathrm{~cm}^{-1}$ might be due to C-H bonds (de Lima Petito et al. 2016). However, after encapsulation, the bands related to RPW extract are overlapped by bands from WPI and sunflower oil. This may indicate the good ratio of carrier materials (i.e. WPI and sunflower oil) used for encapsulation, which consequently lead to formation of satisfactory protection around components of pepper extract.

In order to investigate the surface chemical properties of encapsulates, we applied a Raman spectroscopy/microscopy. As it can be seen in Fig. 1B, the Raman spectrum of RPW extract exhibits two strong bands at $1154 \mathrm{~cm}^{-1}$ and $1515 \mathrm{~cm}^{-1}$, both of which are very close to the bands previously observed in the 
spectrum of the red pepper extract and originate from extracted carotenoids (Withnall et al. 2003). After encapsulation, in the Raman spectra of FDE and SDE, both characteristic bands from pepper carotenoids are observed. This indicates the presence of the RPW extract on encapsulates surface, which is expected for this type of encapsulates.

\section{Figure 1}

Figure 2 illustrates the morphological properties of encapsulates studied by SEM technique. The encapsulation technique had a significant impact on encapsulates morphology. Spray drying resulted in the formation of irregular (non-spherical) particles, with varying diameters and concavities (Fig. 2A-B). Similar observations were reported by Papoutsis et al. (2018) who formation of concavities on the surfaces of the microparticles explained as shrinkage of the particles due to the dramatic loss of moisture after cooling. The external structure of the FDE revealed a non-uniform shape with multiple folds probably being related to the unencapsulated oily phase rich in bioactive compounds (Fig. 2C-D). These results are in accordance with Fioramonti et al. (2017) who investigated morphology of freeze dried flaxseed oil microcapsules.

\section{Figure 2}

\section{Characterization of fortified yogurts}

The enrichment of yogurt with natural bioactive compounds can improve the health and nutritional characteristics of this product. Based on better physicochemical properties, the enrichment of yogurt was carried out with FDE sample and the shelf-life of bioactive compounds was monitored during storage (Fig. 3). Simultaneously, the control yogurt with non-encapsulated RPW extract was prepared. 


\section{Figure 3}

The carotenoid retention over 21 days of storage at $4{ }^{\circ} \mathrm{C}$ is shown in Figure $3 \mathrm{~A}$. As expected, the carotenoid content was influenced by the storage time, as well as the form of bioactive compounds used for yogurt preparation. The retention of carotenoids in control yogurt, during the storage time was $54.79 \%$. On the other hand, enriched yogurt with the encapsulated bioactive compounds successfully retained carotenoids (71.43\%). In the study of Gad et al. (2015) the total carotenoid content in yogurt supplemented with carrot and cantaloupe juice during the storage was monitored. Great decline in the carotenoid content for all samples after cold storage of 12 days was observed. They suggested encapsulation for protection of these bioactive compounds from the outer factors, which is confirmed in our study.

In the case of the polyphenol retention, an increase during the storage period for control yogurt (up to $115.48 \%$ ) and for yogurt with FDE (up to $123.73 \%$ ) was observed (Figure 3B). Tumbas Šaponjac et al. (2016) reported that polyphenol retention in cookies also increased during storage time, suggesting that degradation of the conjugated polyphenols liberates free hydroxyl groups which caused rise to the results of Folin-Ciocalteu assay. Also, degradation of protein aggregates and protein-polyphenol bonds during storage time can lead to increase in polyphenols extractability and their total content, respectively. The same trend was also reported by Arslan and Bayrakci (2016), who investigated antioxidant capacity, composition, and sensory properties of yogurts enriched with persimmon marmalade and puree.

The results of LAB viability during the refrigerated storage period are presented in Table 3. In this study, the both type of fortified yogurts, as well as the control 
sample, were able to maintain the initial number of LAB (over $7 \log \mathrm{CFU} / \mathrm{mL}$ ) during 21 days of shelf life. The determined number of LAB in all tested yogurt types is higher than the recommended therapeutic minimum of $10^{6} \mathrm{CFU} / \mathrm{ml}$ $\mathrm{CFU} / \mathrm{mL}$, which is refer to the minimum of viable $\mathrm{LAB}$ that need to be consumed to obtain the probiotic effect (Senadeera et al. 2018). No significant differences were observed between the control yogurt sample and the samples enriched with RPW extract and FDE, indicating that their application has no influence on the change in viable counts of starter microorganisms. Although it is known that fresh pepper, pepper derived products and pepper waste posse antibacterial and antifungal effect (Karsha and Lakshmi, 2010; Baenas et al. 2019) the results obtained in our study indicate the non-significant effect of RPW on number of LAB during storage. The activity of the pepper waste extracts is usually lower than the activity of fresh paper extracts due to the loss of active compounds during the processing (Loizzo et al. 2015; Baenas et al. 2019). Moreover, the activity of various extracts with antibacterial propertis may be limited by the $\mathrm{pH}$ value of the solvent used in the process of extraction and/or $\mathrm{pH}$ value of the enivronment or fortified products (Ivančajić et al. 2010). Therefore, preservation of active compounds in form of encapsulates is essential for maintaing their stability and effectiveness until the consumption of the enriched product (Casanova and Santos, 2016).

\section{Table 3}

The analysis of attributes by the human senses is a very useful tool in dairy products characterization. Colour and appearance, odour, flavour, body and texture, as well as general acceptability were scored by 7-member sensory panellists using the 1 to 5 intensity scale and results are presented in Fig. 4. Both 
yogurt samples exhibited very good quality and very high scores in terms of general acceptability. However, the utilization of FDE RPW extract in yogurt fortification caused an increase in colour and appearance, flavour, and general acceptability scores.

\section{Figure 4}

In order to increase the acceptability of yogurt, the addition of additives has become an inevitable step in their production. These additives can have effects on the viability of probiotics and starter culture bacteria present in the yogurt. Consequently, additives such as whey protein, casein, lactose, inulin, starch, and others are increasingly used for these purposes (Vinderola et al. 2002). The literature data are in conflicting, therefore in some studies WPC fortified products were preferred by panellist and rejected in others (González-Martínez et al. 2002; Isleten and Karagul-Yuceer, 2006).

\section{Conclusions}

Different encapsulation techniques affected the physicochemical and functional characteristics of the red pepper waste encapsulates. Spray drying method provided lower colour intensity of encapsulates and smaller particle size. Freeze drying method produced the best quality encapsulate in terms of water activity, moisture content, solubility, flowing and colour properties. As freeze drying method proved to be a more efficient technique, enrichment of yogurt was carried out with this encapsulate and the shelf-life of bioactive compounds was monitored during 21 days of storage period. Therefore, it resulted in higher pigment retention during the storage period. On the other hand, an increase of the polyphenol retention was observed for both yogurt samples, which may be associated with the degradation of protein aggregates and increasing in 
polyphenols extractability. Yogurt fortified with freeze dried encapsulates was preferred by panellist due to better colour and appearance, flavour, and general acceptability scores.

\section{Declaration of Interest}

The authors report no declarations of interest.

\section{Acknowledgments}

This research is part of the Projects TR 31044 and III 46010 financed by the Ministry of Education, Science and Technological Development of the Republic of Serbia and COST Action Eurocaroten CA15136.

\section{References:}

Alberts, B., Johnson, A., Lewis, J., Martin, R., Roberts, K., Walter, P., 2007. Molecular biology of the cell, 5th ed. New York: Garland Science.

Al-Saikhan, M.S., Howard, L.R., Miller Jr., J.C., 1995. Antioxidant activity and total phenolics in different genotypes of potato (Solanum tuberosum, L.). Journal of Food Science, 60, 341-343.

Arslan, S., Bayrakci, S., 2016. Physicochemical, functional, and sensory properties of yogurts containing persimmon. Turkish Journal of Agriculture and Forestry, 40, 68-74. Baenas, N., Belović, M., Ilić, N., Moreno, D.A., García-Viguera, C., 2019. Industrial use of pepper (Capsicum annum L.) derived products: Technological benefits and biological advantages, Food Chemistry, 274, 872-885.

Barbosa, M.I.M.J., Borsarelli, C.D., Mercadante, A.Z., 2005. Light stability of spray dried bixin encapsulated with different edible polysaccharide preparations. Food Research International, 38, 989-994.

Barbosa-Canovas, G.V., Ortega-Rivas, E., Juliano, P., Yan, H., 2005. Food powders: physical properties, processing, and functionality, New York: Kluwer/Plenum Publishers.

Batra, G., Gortzi, O., Lalas, S.I., Galidi, A., Alibade, A., Nanos, G.D., 2017. Enhanced antioxidant activity of Capsicum annuum L. and Moringa oleifera L. extracts after encapsulation in microemulsions. ChemEngineering, 1, 15. 
Caleja, C., Barros, L., Antonio, A.L., Carocho, M., Oliveira, M.B.P.P., Ferreira, I.C.F., 2017. A comparative study between natural and synthetic antioxidants: Evaluation of their performance after incorpoation into biscuits. Food Chemistry, 216, 342-346.

Casanova, F., Santos, L., 2016. Encapsulation of cosmetic active ingredients for topical application - A review. Journal of Microencapsulation, 33, 1-17.

Chen, C., Chi, Y.J., Xu, W., 2012. Comparisons on the functional properties and antioxidant activity of spray-dried and freeze-dried egg white protein hydrolysate. Food and Bioprocess Technology, 5, 2342-2352.

Changchub, L., Maisuthisakul, P., 2011. Thermal stability of phenolic extract and encapsulation from mango seed kernel. Agricultural Science Journal, 42, 397-400. de Lima Petito, N., da Silva Dias, D., Costa, V. G., Falcão, D.Q., de Lima Araujo, K.G., 2016. Increasing solubility of red bell pepper carotenoids by complexation with 2hydroxypropyl- $\beta$-cyclodextrin. Food Chemistry, 208, 124-131.

de Souza, V.B., Thomazini, M., Balieiro, J.C.deC., \& Fávaro-Trindade, C.S., 2015. Effect of spray drying on the physicochemical properties and color stability of the powdered pigment obtained from vinification byproducts of the Bordo grape (Vitis labrusca). Food and Bioproducts Processing, 93, 39-50.

Fioramonte, S., Rubiolo, A., \& Santiago, L. 2017. Characterisation of freeze-dried flaxseed oil microcapsules obtained by multilayer emulsions. Powder technology, 319, 238-244.

Firatligil-Durmus, E., Evranuz, O., 2010. Response surface methodology for protein extraction optimization of pepper seed (Capsicum frutescens). Food Science and Technology, 43, 226-231.

Gad, A., Ghita, E., El-Din, H., Badran, S., El-Messery, T., 2015. Evaluation yogurt fortified with vegetable and fruit juice as a natural sources of antioxidant. International Journal of Food and Nutritional Sciences, 4, 21-28.

Ghasemzadeh, A., Jaafar, H.Z.E., Rahmat A., 2010. Antioxidant activities, total phenolics and flavonoids content in two varieties of Malaysia young ginger (Zingiber officinale Roscoe). Molecules, 15, 4324-33.

Girones-Vilaplana, A., Mena, P., Moreno, D.A., Garcia-Viguera, C., 2014. Evaluation of sensorial, phytochemicaland biological properties of new isotonic beverages enriched with lemon and berries during shelf life. Journal of the Science Food and Agriculture, 94, 1090-1100. 
González-Martínez, C., Becerra. M., Cháfer, M., Albors, A., Carot, J.M., Chiralt, A., 2002. Influence of substituting milk powder for whey powder on yoghurt quality. Trends in Food Science and Technology, 13, 334-340

Goula, A.M., Adamopoulos, K.G., 2005. Spray drying of tomato pulp in dehumidified air: II. The effect on powder properties. Journal of Food Engineering, 66, 35-42.

Gustavsson, J., Cederberg, C., Sonesson, U., Van Otterdijk, R., Meybeck, A., 2011. Global food losses and food waste (pp. 1-38). Rome: FAO.

Isleten, M., Karagul-Yuceer, Y., 2008. Effects of functional dairy based proteins on nonfat yogurt quality. Journal of Food Quality, 31, 265-280.

Ivančajić, S., Mileusnić, I., Cenić-Milošević, D, 2010. In vitro antibacterial activity of propolis extracts on 12 different bacteria in conditions of 3 various $\mathrm{pH}$ values, Archives of biological sciences Belgrade, 62, 915-934.

Jinapong, N., Suphantharika, M., Jamnong, P., 2008. Production of instant soymilk powders by ultrafiltration, spray drying and fluidized bed agglomeration. Journal of Food Engineering, 84, 194-205.

Karsha, P.V., Lakshmi, O.B., 2010. Antibacterial activity of black pepper (Piper nigrum Linn.) with special reference to its mode of action on bacteria. Indian Journal of Natural Products and Resources, 1, 213-215.

Khan, F.A., Mahmood, T., Ali, M., Saeed, A., Maalik, A., 2014. Pharmacological importance of an ethnobotanical plant: Capsicum annuum L. Natural product research, 28, 1267-1274.

Loizzo, M.R., Pugliese, A., Bonesi, M., Menichini, F., Tundis, R., 2015. Evaluation of chemical profile and antioxidant activity of twenty cultivars from Capsicum annuum, Capsicum baccatum, Capsicum chacoense and Capsicum chinense: A comparsion between fresh and processed peppers, LWT - Food Science and Technology, 64, 623631.

Markus, F., Daood, H. G., Kapitany, J., Biacs, P. A., 1999. Change in the carotenoid and antioxidant content of spice red pepper (paprika) as a function of ripening and some technological factors. Journal of Agricultural and Food Chemistry, 47, 100-107.

Minguez-Mosquera, M. I., Pérez-Gálvez, A., Garrido-Fernández, J., 2000. Carotenoid content of the varieties jaranda and jariza (Capsicum annuum L.) and response during the industrial slow drying and grinding steps in paprika processing. Journal of Agricultural and Food Chemistry, 48, 2972-2976. 
Nagata, M., Yamashita, I., 1992. Simple method for simultaneous dermination of chlorophyll and Carotenoids in tomato fruit. The Japan Society of Food Science and Technology, 39, 925-928.

Nedović, V., Kalušević, A., Manojlović, V., Petrović, T., Bugarski, B., 2013. Encapsulation Systems in the Food Industry. In: S. Yanniotis, P. Taoukis, N.G Stoforos,.and V.T. Karathanos, eds. Advances in Food Process Engineering Research and Applications, Food Engineering Series. US: Springer, 229-253.

Nedović, V., Mantzouridou, F.T., Đorđević, V., Kalušević, A., Nenadis, N., Bugarski, B.,2017. Isolation, purification and encapsulation techniques for bioctive compounds from agricultural and food production waste. In: Q.V. Vuong, ed. Utilzation of bioactive compounds from agricultural and food waste, Boca Raton: CRC Press Taylor \& Francis Group, 159-195.

Oyaizu, M., 1986. Studies on product of browning reaction from glucose amine. The Japanese Journal of Nutrition and Dietetcs, 44, 307-315.

Papoutsis, K., Golding, J.B., Vuong, Q., Pristijono, P., Stathopoulos, C.E., Scarlett, C.J., Bowyer, M., 2018. Encapsulation of Citrus By-Product Extracts by Spray-Drying and Freeze-Drying Using Combinations of Maltodextrin with Soybean Protein and 1Carrageena. Foods, 7, 115.

Pop, M., Lupea, A. X., Popa, S., Gruescu, C., 2010. Colour of bilberry (Vaccinium myrtillus fruits) extracts. International Journal of Food Properties, 13, 771-777.

Que, F., Mao, L., Fang, X., Wu, T., 2008. Comparison of hot air-drying and freezedrying on the physicochemical properties and antioxidant activities of pumpkin (Cucurbita moschata Duch.) flours. International Journal of Food Science and Technology, 43, 1195-1201.

Rao, A., Shallo, H.E., Ericson, A.P., Thomas, R.L., 2002. Characterization of soy protein concentrate produced by membrane ultrafiltration. Journal of Food Science, 67, $1412-1418$.

Rascón, M. P., Beristain, C. I., García, H. S., Salgado, M. A., 2011. Carotenoid retention and storage stability of spray-dried encapsulated paprika oleoresin using gum arabic and soy protein isolate as wall materials. Food Science and Technology, 44, 549557.

Russo, V.M., Howard, L.R., 2002. Carotenoids in pungent and non-pungent peppers at various developmental stages grown in the field and glasshouse. Journal of the Science of Food and Agriculture, 82, 615-624. 
Sandoval-Castro, C.J., Valdez-Morales, M., Oomah, B.D., Gutierrez-Dorado, R., Medna-Godoy, S., Espinosa-Alonso, L.G., 2017. Bioactive compounds and antioxidant activity in scalded Jalapeño pepper industrial byproduct (Capsicum annuum). Journal of Food Science and Technology, 54, 1999-2010.

Šeregelj, V., Ćetković, G., Čanadanović-Brunet, J., Tumbas-Šaponjac, V., Vulić, J., Stajčić, S., 2017. Extraction and encapsulation of bioactive compounds from carrots. Acta Periodica Technologica, 48, 261-273.

Shaimaa, G.A., Mahmoud, M.S., Mohamed, M.R., Emam, A.A., 2016. Effect of heat treatment on phenolic and flavonoid compounds and antioxidant activities of some Egyptian sweet and chilli pepper. Natural Products Chemistry \& Research, 4, 218.

Shori, A.B., Rashid F., Baba A.S., 2018. Effect of the addition of phytomix-3+ mangosteen on antioxidant activity, viability of lactic acid bacteria, type 2 diabetes keyenzymes, and senzory evaluation of yogurt. Food Science and Technology, 94, 33-39.

Tumbas Šaponjac, V., Girones-Vilaplana, A., Djilas, S., Mena, P., Ćetković, G., Moreno, D.A., Čanadanović-Brunet, J., Vulić, J., Stajčić, S., Krunić, M., 2014. Anthocyanin profiles and biological properties of caneberry (Rubus spp.) press residues. Journal of the Science of Food and Agriculture, 94, 2393-2400.

Tumbas Šaponjac, V., Gironés-Vilaplana, A., Djilas, S., Mena, P., Ćetković, G., Moreno, D. A., Čanadanović-Brunet, J., Vulić, J.,Stajčić, S., Vinčić, M. 2015. Chemical composition and potential bioactivity of strawberry pomace. RSC Advances, 5, 53975405.

Tumbas Šaponjac, V., Ćetković, G., Čanadanović-Brunet, J., Pajin, B., Djilas, S., Petrović, J., Vulić, J., 2016. Sour cherry pomace extract encapsulated in whey and soy proteins: Incorporation in cookies. Food Chemistry, 207, 27-33.

Turkmen, N., Sari, F., Velioglu, Y.S., 2006. Effect of extraction solvents on concentration and antioxidant activity of black and black mate polyphenols determined by ferrous tartrate and Folin-Ciocalteu methods. Food Chemistry, 99, 838-841.

Victória, R., Fernandes, B., Borges, S.V., Botrel, D.A., 2013. Influence of spray drying operating conditions on microencapsulated rosemary essential oil properties. Ciênciae Tecnologia de Alimentos, 33, 171-178.

Vinderola, C.G., Costa, G.A., Regenhardt, S., Reinheimer, J.A., 2002. Influence of compounds associated with fermented dairy products on the growth of lactic acid started and probiotic bacteria. International Dairy Journal, 12, 579-589. 
Withnall, R., Chowdhry, B.Z., Silver, J., Edwards, H.G.M., de Oliveira, L.F.C., 2003. Raman spectra of carotenoids in natural products. Spectrochimica Acta Part A, 59, 2207-2212.

Zhuang, Y., Chen, L., Sun, L., Cao, J., 2012. Bioactive characteristics and antioxidant activities of nine peppers. Journal of Functional Foods, 4, 331-338. 


\section{Figure captions}

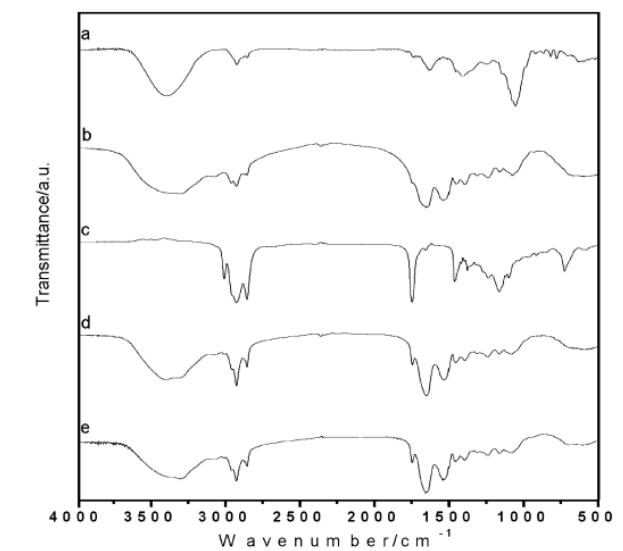

A)

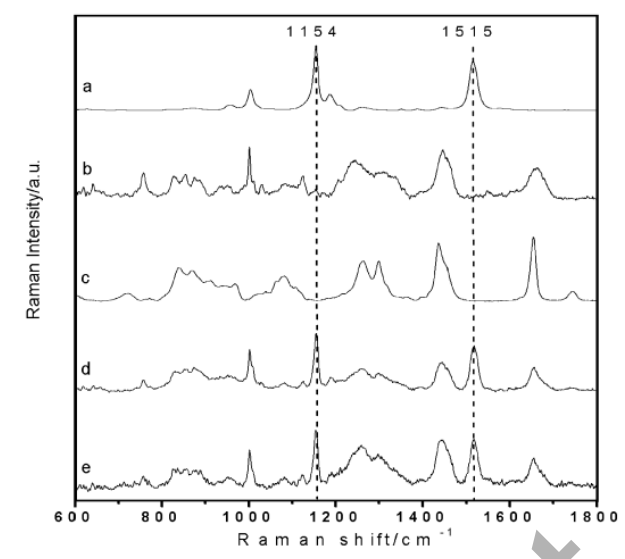

B)

Figure 1. (A) FTIR spectra and (B) Raman spectra of: (a) red pepper waste (RPW) extract; (b) whey protein isolate (WPI); (c) sunflower oil; (d) freeze dried encapsulate (FDE); (e) spray dried encapsulate (SDE).
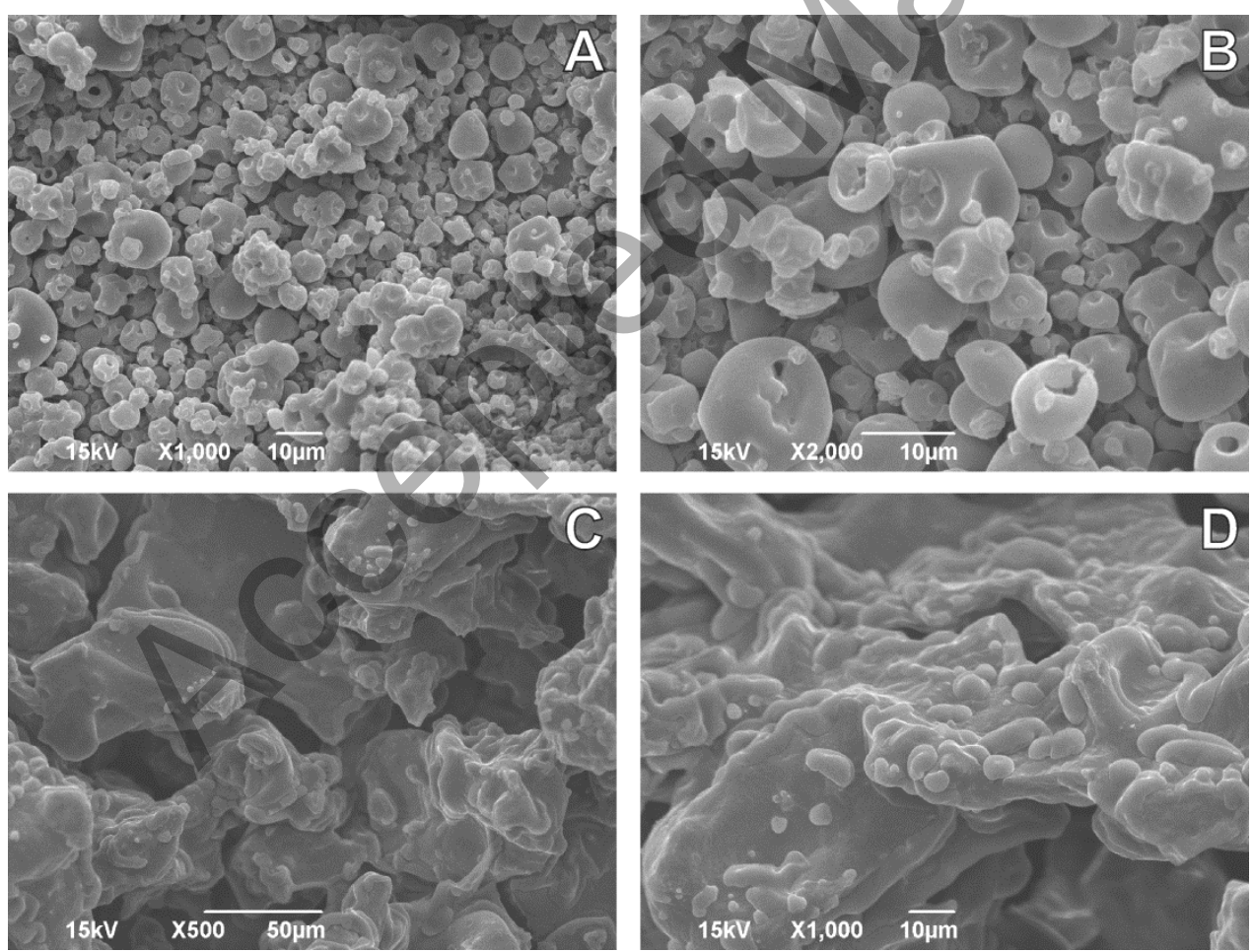

Figure 2. Scanning electron morhology properties of spray dried (SDE) and freeze dried (FDE) encapsulates with magnification of 1000 (A), 2000 (B), 500 (C) and 1000 (D). 


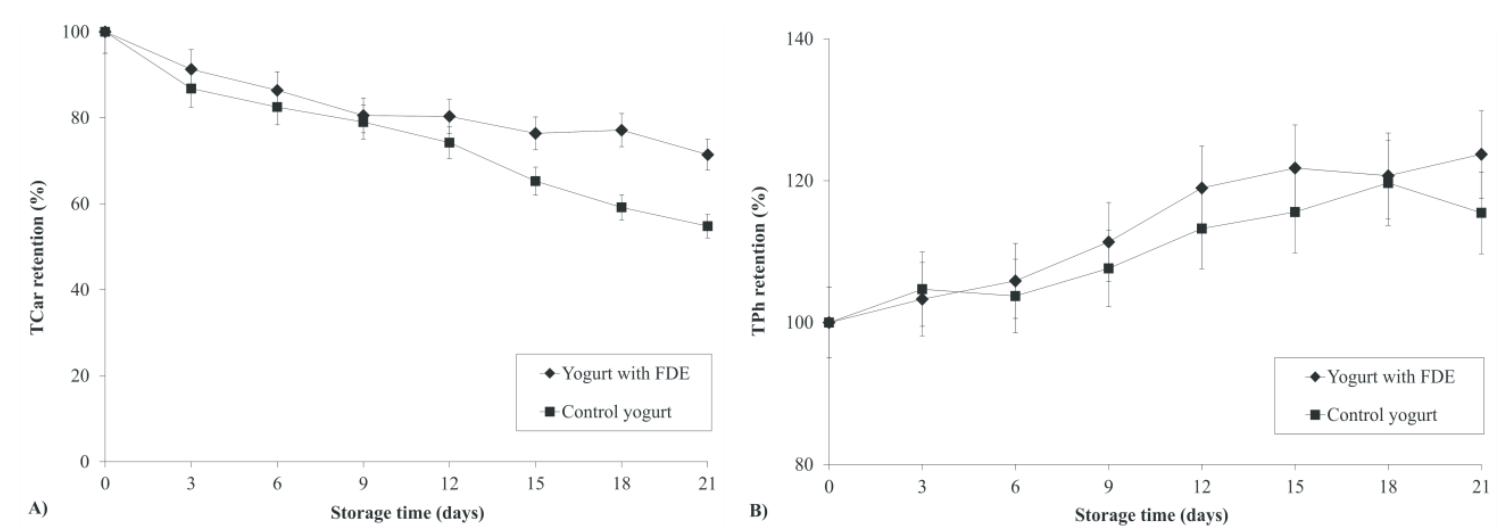

Figure 3. (A) Carotenoid (TCar) and (B) polyphenol (TPh) stability in yogurt with freeze dried encapsulate (FDE) and control yogurt during storage period.

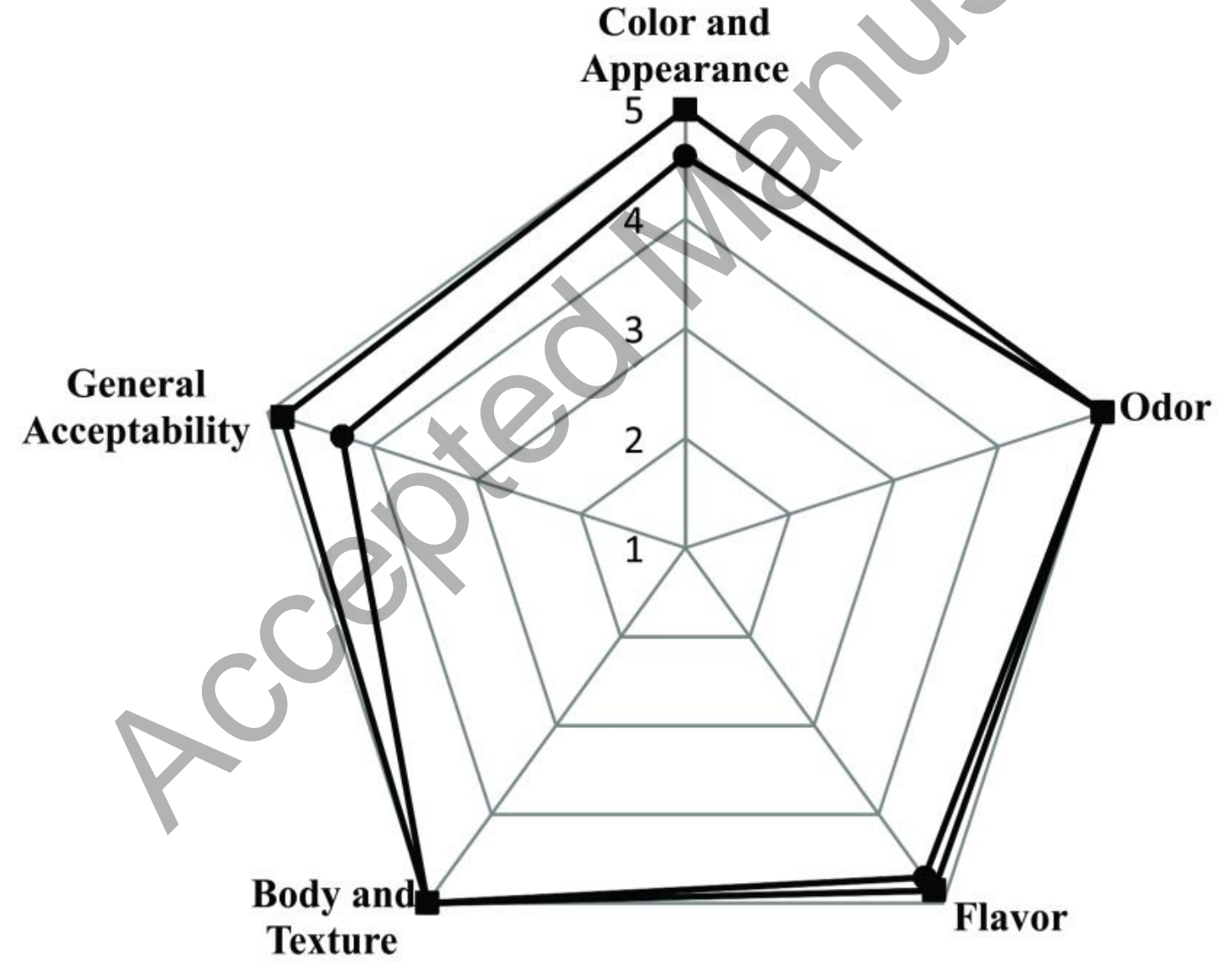

Figure 4. Sensorial attributes of yogurt with freeze dried encapsulate (FDE) and control yogurt. 
Table 1. The content of bioactive compounds and antioxidant activity of red pepper waste (RPW) extracts. The results are represented as the means \pm standard deviation (n $=3)$.

\begin{tabular}{|c|c|c|}
\hline $\begin{array}{c}\text { Bioactive compounds / } \\
\text { Antioxidant activity }\end{array}$ & $\begin{array}{c}100 \%(\mathrm{v} / \mathrm{v}) \text { acetone } \\
\text { RPW extract }\end{array}$ & $\begin{array}{r}\text { Mixture of } 36 \%(\mathrm{v} / \mathrm{v}) \\
\text { acetone and } 64 \%(\mathrm{v} / \mathrm{v}) \\
\text { ethanol RPW extract }\end{array}$ \\
\hline $\begin{array}{l}\text { Total carotenoid content } \\
\qquad(\text { TCar })^{\mathrm{a}}\end{array}$ & $53.61 \pm 0.03$ & $63.97 \pm 0.01$ \\
\hline Total phenolic content $(\mathrm{TPh})^{\mathrm{b}}$ & $698.29 \pm 0.34$ & $1201.5 \pm 0.51$ \\
\hline$\beta$-carotene & $6.45 \pm 0.02$ & $6.51 \pm 0.01$ \\
\hline Lutein & $0.47 \pm 0.00$ & $4.03 \pm 0.06$ \\
\hline Zeaxanthin & $0.53 \pm 0.00$ & $1.07 \pm$ \\
\hline$\beta$-cryptoxanthin & $2.22 \pm 0.01$ & $0.21 \pm 0.00$ \\
\hline Gallic acid ${ }^{c}$ & $171.41 \pm 0.25$ & 0.26 \\
\hline Vanillic acid ${ }^{\mathrm{c}}$ & $52.41 \pm 0.14$ & \pm 0.14 \\
\hline Protocatechuic acid ${ }^{\mathrm{c}}$ & $85.32 \pm 0.17$ & \pm 0.16 \\
\hline Sinapinic acid ${ }^{c}$ & $17.99 \pm 0.03$ & $51.86 \pm 0.09$ \\
\hline Caffeic acid ${ }^{\mathrm{c}}$ & $120.54 \pm 0$. & $250.01 \pm 0.36$ \\
\hline Rosmarinic acid ${ }^{\mathrm{c}}$ & $12.08 \pm 0.01$ & $42.20 \pm 0.05$ \\
\hline Chlorogenic acid ${ }^{\mathrm{c}}$ & $4.67 \pm 0.01$ & $1.70 \pm 0.00$ \\
\hline Epicatechin $^{c}$ & .12 & $6.13 \pm 0.01$ \\
\hline Rutin $^{c}$ & .06 & $21.20 \pm 0.04$ \\
\hline Quercetin $^{c}$ & $4.11 \pm 0.01$ & $4.02 \pm 0.00$ \\
\hline Myricetin $^{c}$ & $21.36 \pm 0.03$ & $4.24 \pm 0.01$ \\
\hline DPPH assay $\left(\mathrm{AC}_{\mathrm{DPPH}}\right)^{\mathrm{d}}$ & $216.20 \pm 5.04$ & $1018.21 \pm 1.01$ \\
\hline Reducing power $(\mathrm{RP})^{\mathrm{d}}$ & $408.25 \pm 1.28$ & $3520.63 \pm 10.29$ \\
\hline ABTS assay $\left(\mathrm{AC}_{\mathrm{ABTS}}\right)^{\mathrm{d}}$ & $164.02 \pm 3.36$ & $1556.86 \pm 20.53$ \\
\hline $\begin{array}{c}\beta \text {-carotene bleaching assay } \\
\left(\mathrm{AC}_{\mathrm{BCB})}\right)^{\mathrm{e}}\end{array}$ & $73.29 \pm 3.55^{*}$ & $74.08 \pm 2.48^{*}$ \\
\hline
\end{tabular}

${ }^{\mathrm{a}}$ Expressed as mg $\beta$-carotene/100 g; ${ }^{b}$ Expressed as mg GAE/100 g; ${ }^{\mathrm{c}}$ Expressed as $\mathrm{mg} / 100 \mathrm{~g} ;{ }^{\mathrm{d}}$ Expressed as $\mu \mathrm{mol} / \mathrm{TE} 100 \mathrm{~g} ;{ }^{\mathrm{e}}$ Expressed as percent of inhibition relative to control. * Denotes that the mean difference is not significant at the 0.05 level. 
Table 2. Physical properties of spray dried (SDE) and freeze dried (FDE) encapsulates. The results are represented as the means \pm standard deviation $(n=3)$.

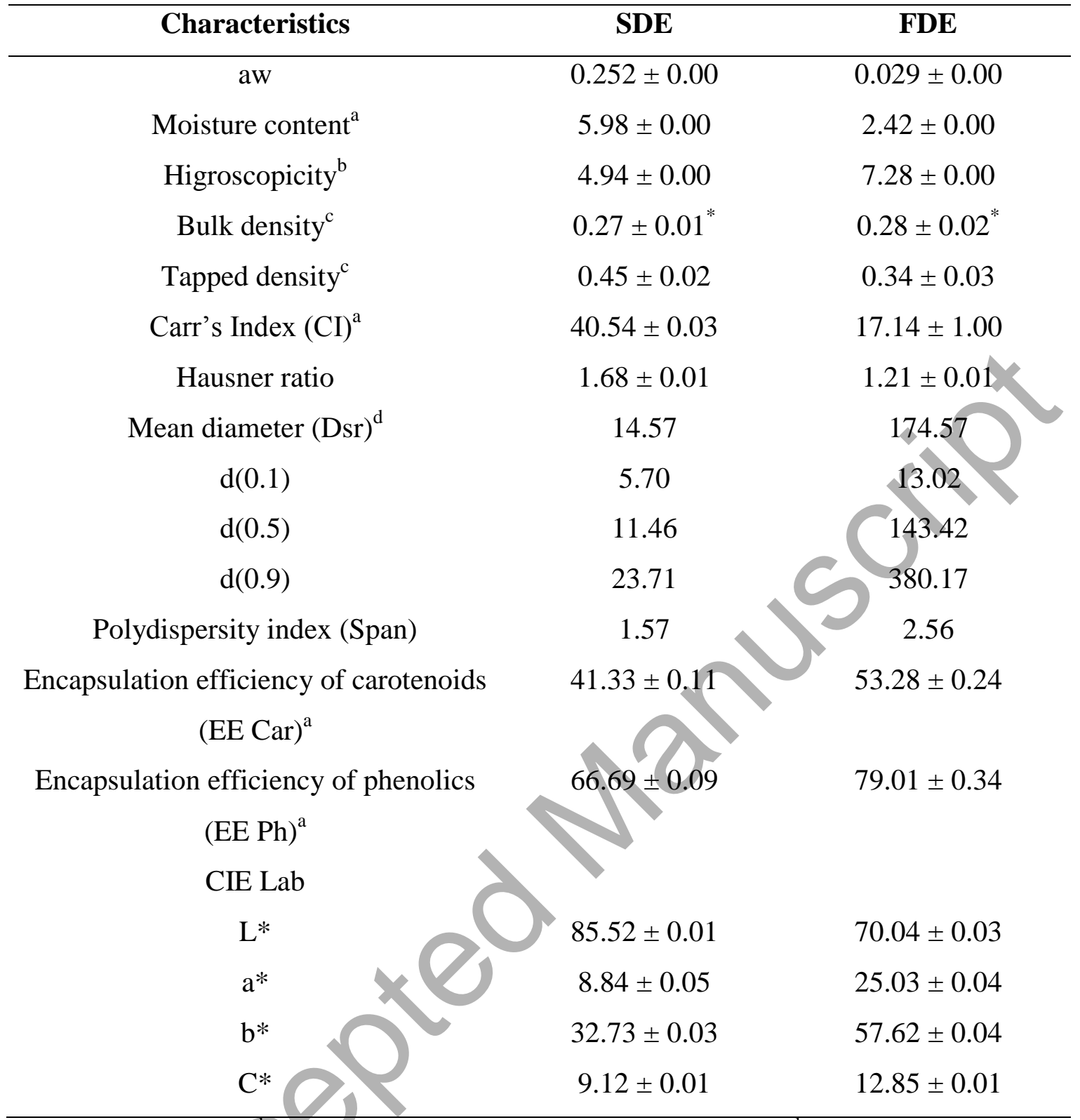

\footnotetext{
${ }^{\mathrm{a}}$ Expressed as \%; ${ }^{\mathrm{b}}$ Expressed as g/100 g; ${ }^{\mathrm{c}}$ Expressed as $\mathrm{g} / \mathrm{mL} ;{ }^{\mathrm{d}}$ Expressed as $\mu \mathrm{m} .{ }^{*}$
} Denotes that the mean difference is not significant at the 0.05 level. 
Table 3. Changes in the viable counts of lactic acid bacteria LAB of different yogurt samples during refrigerated storage period. The results are represented as the means \pm standard deviation $(\mathrm{n}=3)$.

Yogurt sample

Viability of LAB during storage period

21 days

$\begin{array}{lll}\text { Control yogurt } & 7.38 \pm 0.01^{*} & 7.35 \pm 0.02^{*}\end{array}$

(with red pepper waste extract)

Yogurt with freeze dried encasulates

$7.39 \pm 0.05^{*} \quad 7.33 \pm 0.01^{*}$

Natural yogurt

$7.43 \pm 0.03^{*}$

$7.34 \pm 0.02$

${ }^{\mathrm{a}} \log \mathrm{CFU} / \mathrm{mL} ;{ }^{*}$ Denotes that the mean difference is not significant at the 0.05 level. 